\title{
Patient survey to identify reasons for non-adherence and elicitation of quality of life concepts associated with immunosuppressant therapy in kidney transplant recipients
}

\author{
This article was published in the following Dove Press journal: \\ Patient Preference and Adherence \\ 12 January 2016 \\ Number of times this article has been viewed
}

\author{
Gorden Muduma' \\ Francis C Shupo ${ }^{2}$ \\ Sophie Dam ${ }^{3}$ \\ Natalia A Hawken ${ }^{3}$ \\ Samuel Aballéa ${ }^{3}$ \\ Isaac Odeyemi' \\ Mondher Toumi ${ }^{4}$ \\ 'Astellas Pharma Europe Ltd, \\ Chertsey, ${ }^{2}$ Creativ-Ceutical Ltd, \\ London, UK; ${ }^{3}$ Creativ-Ceutical Ltd, \\ Paris, ${ }^{4}$ Public Health (EA 3279), \\ Faculty of Medicine, Aix-Marseille \\ University, Marseille, France
}

Background: Renal transplantation (RT) is considered the treatment of choice for end-stage renal disease compared to dialysis, offering better health-related quality of life (HRQoL) and higher survival rates. However, immunosuppressants are essential for the long-term survival of kidney grafts and patients' non-adherence to their medication leads to poor outcomes. Immunosuppressants can also significantly alter patients' HRQoL because of their side effects and the complex chronic medication regimen they represent.

Purpose: To elicit key concepts related to adherence to immunosuppressant therapy (IT) and reasons for non-adherence in terms of patient reported outcomes, side effects, and the impact of the medication on HRQoL in RT population, including patient preference of once daily over twice-daily immunosuppressive regimen. Results were used to develop an IT-specific conceptual framework and provide suggestions for improving patients' adherence to IT.

Materials and methods: Interviews were conducted with three clinical experts to determine key concepts related to RT and immunosuppressants. Thirty-seven participants in four focus groups were asked to cite important concepts related to adherence and impact of IT on HRQoL and to rate them. Qualitative analysis was conducted to code participants' responses.

Results: Non-adherence among participants where admitted was unintentional. The reason for this included forgetfulness, interference with lifestyle, being asleep at the time the medication should be taken, change in routine, and impact of side effects. Overall, participants reported that the evening dose was more problematic to remember and that the exclusion of this dose could make them more adherent. Participants also reported that IT impacted on their HRQoL in a number of ways including: placing restrictions on their lifestyle, causing anxiety, or impairing their ability to work.

Conclusion: This study provides qualitative evidence about the barriers to IT adherence and the components of HRQoL that are important from the perspective of RT patients. The developed conceptual framework of IT-HRQoL in RT transplants, including social, psychological, and work life domains, can be used to inform the development of a new IT-specific measure of HRQoL in RT patients for use in head-to-head clinical trials or observational studies. Despite limitations associated with the number and the age range of patients recruited, this study suggests that a change in the regimen from twice-daily to once daily among other measures could improve their adherence to IT and their HRQoL by placing less restrictions on their lifestyles.

Keywords: adherence, PRO, conceptual framework, immunosuppressant, renal transplantation, QoL

\section{Background}

Renal transplantation (RT) is considered the treatment of choice for end-stage renal disease compared to with chronic dialysis treatment, offering better health-related 
quality of life (HRQoL), and higher survival rates. ${ }^{1,2}$ However, kidney transplant benefits are heavily dependent on immunosuppressant therapy (IT) following organ transplantation. Immunosuppressants are a vital component of the multifaceted medical regimen in RT recipients, preventing graft rejection, resumption of dialysis, or death. ${ }^{3}$ Whereas strict adherence to immunosuppressant medication is essential for the long-term survival of kidney grafts, it has been shown that immunosuppressants are one of the most common groups of prescription drugs to which post-transplant patients are nonadherent. ${ }^{4}$ Renal transplant recipients are especially prone to non-adherence because of the complexity and life-long character of their immunosuppressive therapeutic regimen. Depending on the method and the operational definition used, rates of immunosuppressant non-adherence among the RT population are reported to range from $2 \%$ to $67 \%,{ }^{5}$ with such wide ranges reflecting the difficulty of correctly defining and quantifying the phenomenon.

Several studies have demonstrated that even minor variations from the prescribed IT are associated with an increased risk of poor outcomes for transplant recipients. ${ }^{2,6}$ Suboptimal adherence to the immunosuppressive regimen causes a higher risk of late acute rejection and allograft loss. ${ }^{7}$ A meta-analysis by Butler et $\mathrm{al}^{8}$ found that 36\% (95\% confidence interval [CI], 14\%-65\%) of graft losses were associated with prior non-adherence. Non-adherence to IT also accounts for approximately half of the graft failures due to rejection; ${ }^{9}$ graft failure has been reported to be higher among non-adherent patients, with odds increasing sevenfold (95\% CI, 4\%-12\%: $P<0.001){ }^{8}$ Another study on the subject by Vlaminck et al ${ }^{10}$ supported the Butler et $\mathrm{al}^{8}$ study, reporting significantly higher outcomes among non-adherent patients compared with the compliant group $(21.2 \%$ vs $8 \%, P<0.05)$.

Kidney transplantation may improve the HRQoL of patients on dialysis ${ }^{11}$ from a physical, psychological, social, or from a general well-being perspective, and release the patient from the daily constraints associated with dialysis. Nonetheless, immunosuppressants can significantly alter patients' HRQoL because of their potential side effects and the complex chronic medication regimen they represent. Many studies have investigated the HRQoL associated with RT post-transplant, ${ }^{12-15}$ but to our knowledge only one has used a qualitative design in the context of focus groups to explore patients' attitudes to medication adherence in this population. ${ }^{16}$ However, no qualitative study has elicited the important concepts related to the impact of IT on HRQoL and encapsulate its findings in a conceptual framework. The reasons for non-adherence were also identified in numerous analyses and many efforts have been made to target interventions to these factors, ${ }^{17,18}$ but only a few studies have been conducted considering patients' input, which is critical in a behavioral phenomenon such as nonadherence. Understanding the connection between IT and HRQoL from patients' perspective is important to explore the processes underlying adherent behavior and to develop appropriate remedies that could significantly improve transplant outcomes.

The objectives of this study were to elicit, through interviews and focus groups, key concepts related to adherence to IT and reasons for non-adherence in terms of patient reported outcomes, side effects and the impact of the medication on HRQoL in RT population including patient preference of once daily over twice-daily immunosuppressive regimen. Results were used to develop a conceptual framework depicting the process by which the different influencing factors affect patients' HRQoL as well as to make suggestions for what could improve patients' adherence to IT.

\section{Materials and methods Literature review}

A literature review was conducted following a search of Embase/PubMed to collect published evidence on the impact of IT on patients' adherence and HRQoL prior to patient interviews, focusing on patient reported outcomes and adherence to IT after RT.

Studies published from 2003 onwards were analyzed in order to identify barriers to IT adherence. Clinical guidelines and summaries of product characteristics for immunosuppressant treatments were also reviewed.

\section{Study design}

The study protocol was submitted for review to the UK National Research Ethics Service, which classified the study as research for which ethical approval was not required given the non-interventional nature of the study and that information identifying participants was not collected, either during focus group interviews or at any other point during the research. This study was performed in accordance with the Declaration of Helsinki. Participants each received an information leaflet containing a detailed explanation of the purpose and format of the study, and were given a few days' reflection time to decide whether to participate in a single interview. Before inclusion in the study, the recruiter ensured that participants understood the information they had been given and that their decision to participate was made freely. At the start of each interview, the interviewer also reminded the participants 
of the purpose and format of the interview as described in the leaflet, while reminding them of their right to withdraw from the interview without needing to give a reason. Each participant provided their written informed consent, prior to enrolment, to the Renal Transplant Centre where they were recruited. At the completion of each group interview, a quick summary of the discussion was given, based on notes collected, giving the participants the opportunity to comment, explain, clear up any misunderstandings, or add any points they felt were not properly understood. Participants were also invited, if they wished, to make private comments directly to the researchers after the session or via the recruiter at the centre. There were no private comments made or concerns raised by the participants either directly to the researchers or via the recruiting centre following the focus group interviews.

A semi-structured one-on-one interview was conducted with a nephrologist and two nephrology nurses working at the transplant unit in Nottingham (UK) in order to understand the reasons for non-adherence. In the light of previously gathered information from both literature and clinical experts, a discussion guide was developed to be used with patients in focus groups. Specifically, insights into the impact of IT on adherence and HRQoL were identified and grouped into HRQoL domains to assist the discussion. Both patients' perspective (focus groups) and clinical experts' perceptions (interviews) on patients' behavior were incorporated to generate a comprehensive list of patient-derived themes. Four focus group interviews were conducted at Renal Transplantation Centers: two in Hammersmith, London, and two in Nottingham. The setting for discussions incorporated recommendations for good practice, ${ }^{19}$ including ensuring participant comfort, manageable group size, and having round-table seating. The ground rules were established and the objective of the discussion explained by the facilitator. All focus groups were conducted in English by an experienced psychologist with the assistance of a second researcher who recorded field notes.

Three main areas were discussed: 1) patients' perceptions on adherence to IT, including how they took or take them and reasons for not taking them as prescribed; 2) impact of IT on their lives, including the potential benefits, and side effects of IT; 3 ) suggestions for what could have helped them take their medication and improved their adherence to IT.

Each group was asked the same set of open-ended questions, and each focus-group session lasted 1 hour. Participants gave opinions on a voluntary basis and were reimbursed for their travel expenses after the interviews.

\section{Patient recruitment}

Two practicing nephrology nurses recruited patients for the focus group sessions. Patients suspected to be non-adherent to IT attending London and Nottingham Transplant Centres were recruited to participate in the focus groups. Patients were eligible for this study if they met the following criteria: 1) over 18 years old; 2) known to be non-adherent to IT; 3) with kidney graft for at least 6 months duration before enrolment. On the other hand, patients were excluded if they: 1) had major physical dysfunction (eg, kidney failure); 2) had axis one disorder (anxiety, eating, psychotic, dissociative, and substance use disorders - except nicotine dependence); 3) had cognitive impairment as judged by their clinical team.

\section{Data collection and analysis}

Digital recordings of the focus group sessions were transcribed verbatim and a qualitative analysis was undertaken to code participants' responses using the ATLAS/ti qualitative analysis software, 7.1 (Scientific Software Development, Berlin, Germany). Concepts elicited from patients were listed by two independent researchers and those regarding the impact of IT on QoL were proposed to two clinical experts who were asked to classify them into themes. Concepts not related to IT adherence were ignored. Any discrepancies between experts were discussed and resolved by consensus.

\section{Results}

\section{Interview with nephrology nurses}

When asked if they could identify particularly non-adherent groups, the nurses indicated that patients under 25 years of age were the least adherent. They explained that this was due to the transition from adolescence to being a young adult patient, which is often problematic. They noted that young adults often felt invincible and were not fully aware of the consequences of non-adherence. The nurses added that young adults tended to have lifestyles that conflicted with good adherence from their observation; they often went out and forgot the evening doses after having consumed alcohol, or returned home too late for the evening dose, and were still asleep at the time of their morning dose. Young adults were more impulsive and would unexpectedly go out without their medication resulting in non-adherence. The nurses reported that the elderly also represented a notable group of non-adherent patients. As with adolescent patients, they tended to forget the evening doses, but they were more adherent with the morning dose. According to the nurses, middle-aged patients were more likely to be adherent, 
especially patients with social support from partners or extended family.

Nurses ranked the reasons for non-adherence as follows: 1) Forgetting to take the medication. 2) Pill burden: patients complained about the pill burden, which was too high on a daily basis. Pills were randomly taken without paying full attention to the specific requirement of each one. 3) Lifestyle: a) Going out and drinking alcohol then, forgetting to take a dose. b) Forgetting to bring medication when going out. Nurses also reported that patients on a twice-daily dose regimen requested to be put on a once-daily dose regimen because of the daily pill burden. Patients were also aware that they could still take a dose within the 2-hour window if they missed the timing.

\section{Focus groups}

\section{Patients' characteristics}

A total of 40 RT patients were enrolled in the study, 37 of whom (18 females and 19 males) participated in the four focus group interviews. The average age of patients was 50.1 years and ranged from 29 to 68 years. Of the 37 participants, 32 received a first kidney transplant, four received a second transplant, and one received a third transplant. In total, seven participants had received transplants from living related donors, while 30 were transplanted from cadavers. Seventeen patients out of 37 were on a once-daily dosing regimen and most of them were from Nottingham (Table 1).

\section{Perception of adherence}

Participants emphasized the importance of adherence to IT toward keeping the graft and themselves healthy and dialysis free. Adherence was also explained in terms of the sense of obligation to care for the donated organ, and equally out of consideration to avert the burden of the patient's care on relatives:

"Somebody's died. He gave me a kidney, so I've got to

look after it." (Male, age 35)

"I don't want my wife to take care of me on dialysis.

So I'll do anything [...]" (Male, age 67)

However, even in this highly motivated group, participants reported occasional non-adherence. Only four out of $37(10.8 \%)$ participants reported full adherence. The frequency of non-adherence varied among participants from once a fortnight to once in 20 years. Only one participant reported deliberately omitting doses of their immunosuppressive medication for four to five consecutive days, resulting in a rise in blood count that scared them back to adherence.

\section{Reasons for non-adherence}

Patients identified several reasons for non-adherence. Primarily, non-adherence was due to forgetfulness with disruption of routine cited as an important element involved in both morning and evening doses:

“[...] in my set routine, then I don't forget [...] if I got like a very busy few weeks I might forget [...]” (Female, age 36)

Miscalculations, mixing the dose with other medicines, vomiting, or being under the influence of alcohol were also cited as reasons for non-adherence.

For participants on the twice-daily dosing, non-adherence was attached to either of the doses. Seventeen of the 20 participants on a twice-daily dosing preferred the morning dose to the evening, as routines were more prone to disruptions in the evening:

Table I Patients' distribution and characteristics by focus group*

\begin{tabular}{|c|c|c|c|c|}
\hline & $\begin{array}{l}\text { Focus group I } \\
\text { (London) }\end{array}$ & $\begin{array}{l}\text { Focus group } 2 \\
\text { (London) }\end{array}$ & $\begin{array}{l}\text { Focus group } 3 \\
\text { (Nottingham) }\end{array}$ & $\begin{array}{l}\text { Focus group } 4 \\
\text { (Nottingham) }\end{array}$ \\
\hline Number of patients & 8 & 8 & 10 & II \\
\hline \multicolumn{5}{|l|}{ Sex, N (\%) } \\
\hline Male & $4(50 \%)$ & $6(75 \%)$ & $4(40 \%)$ & $5(45.5 \%)$ \\
\hline Female & $4(50 \%)$ & $2(25 \%)$ & $6(60 \%)$ & $6(54.5 \%)$ \\
\hline \multicolumn{5}{|l|}{ Type of donor, N (\%) } \\
\hline Living & I (I2.5\%) & $2(25 \%)$ & $2(20 \%)$ & $2(18.2 \%)$ \\
\hline Cadaveric & 7 (87.5\%) & $6(75 \%)$ & $8(80 \%)$ & 9 (81.8\%) \\
\hline \multicolumn{5}{|l|}{ Age (years) } \\
\hline Mean & 55.8 & 44.1 & 53.0 & 47.6 \\
\hline Range & $46-68$ & $35-58$ & $43-67$ & $29-60$ \\
\hline \multicolumn{5}{|l|}{ Daily dosing, N (\%) } \\
\hline Once & $3(37.5 \%)$ & $2(25 \%)$ & $4(40 \%)$ & $8(72.7 \%)$ \\
\hline Twice & $5(62.5 \%)$ & $6(75 \%)$ & $6(60 \%)$ & $3(27.3 \%)$ \\
\hline
\end{tabular}

Notes: Calculations were based on the number of participants in the respective focus group. *Elderly ( $>68$ years), children ( $<18$ years), and young adult ( $18-25$ years) patients are not included in this analysis. 
"[...] we obviously want less pills so if we only have to take them, that one in the morning, we' $d$ rather have one less." (Male, age 68)

All participants but one had other tablets to take in addition to their immunosuppressive medication and expected the once daily to be easier to remember and combine with their lifestyles. They also expected one less pill to "forget", and the insomnia associated with the evening dose to be avoided. However, two participants mentioned that they were comfortable in their routines of taking two doses daily, and were unwilling to switch to the alternative.

\section{Strategies to reduce non-adherence}

Patients were asked to provide the strategies they use to remember to take their medication. Their strategies of remembering included reminders from spouses, children, or colleagues, pill organizers or pill boxes, and telephone alarms:

“I say, 'Look, don't let me forget it is 10 o' clock' [...] I've

a reminder on my calendar [...]" (Male, age 56)

When travelling, patients stocked up on medication, which they kept in both carry-on and checked luggage, and paid attention to changes in time zones.

\section{Impact of being on IT}

Many participants reported being anxious about the timing and dose of their medication, the interaction between IT and other medication, as well as exposure to the sun to reduce the risk of skin cancer:
"It rules your life [...] it makes your life a bit difficult."

(Male, age 44)

\section{Side effects of IT and QoL}

Many patients expressed concerns about the side effects of IT. Numerous side effects were mentioned, with only two participants mentioning having none. Table 2 depicts the side effects reported by participants.

Nonetheless, across participants, it was unanimous that IT had global benefit on QoL. They shared a feeling of gratitude for their organ and felt lucky to be alive. The escape from dialysis was a relief and participants felt physically better. Also, leading a more "normal" life improved their confidence. Side effects were a small price to pay as IT was keeping their graft functioning:

"I'd much rather have sweats for half an hour than be on dialysis." (Female, age 53)

"[...] can't explain to anybody, all these side effects.

[...] And a lot of people don't want to know, I end up [...]

not telling anybody anything." (Female, age 57)

Despite the general consensus that the advantages of IT outweighed the disadvantages, the burden of side effects on daily life had a psychological impact on patients as well as on their work and social life.

\section{Impact of IT on work life}

Some participants reported that side effects were so severe that new job roles were required. A role change away from

Table 2 Side effects reported by participants in focus groups*

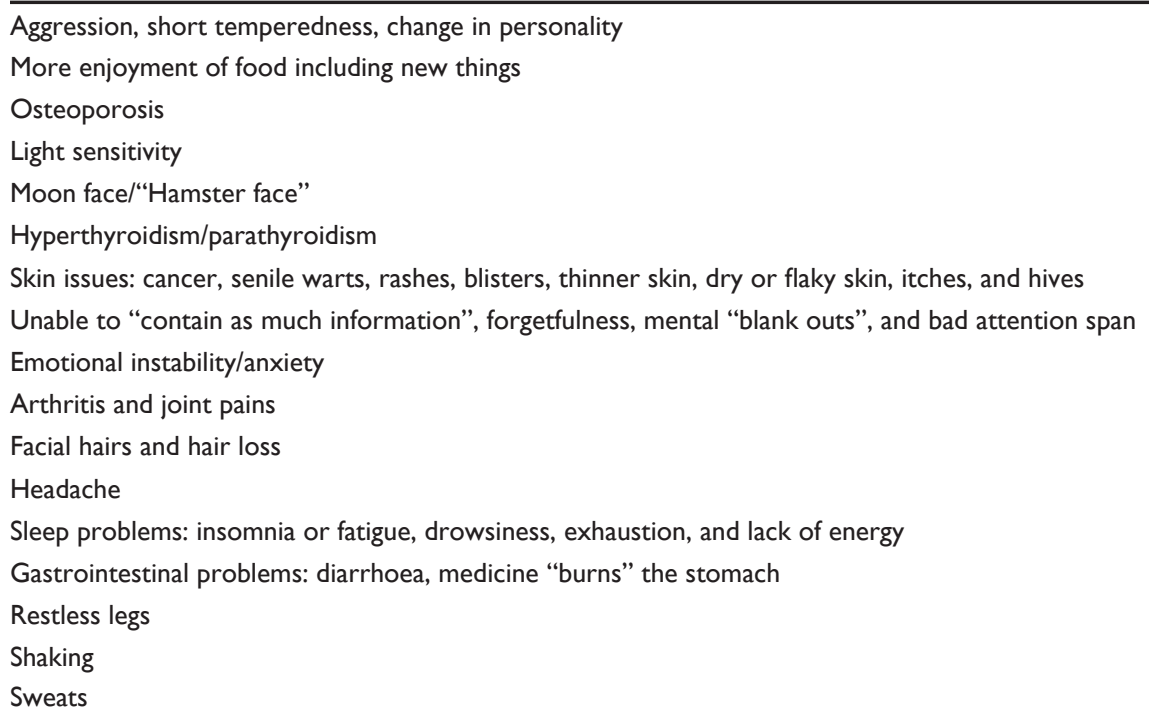

Notes: Side-effects associated with IT as reported by participants in the four focus groups regardless of the frequency. *Elderly $(>68$ years), children $(<18$ years), and young adults (18-25 years) patients are not included in this analysis.

Abbreviation: IT, immunosuppressant therapy. 
machines due to shakes was reported by a participant, while the inability to concentrate was the reason given when another was offered an alternative role requiring less reading. Poor memory affected some participants' work, causing them to be less productive due to "zoning out" more frequently. One participant stopped working altogether due to fear of infection. However, another mentioned having more energy and being more productive:

"It's impacted my work. [...] sweat would be pouring down me, it's embarrassing [...]" (Male, age 44)

"[...] I have more energy [...] getting more out of my

day. [...] and getting more out of my work." (Male, age 35)

\section{Impact of IT on social life}

A number of patients noted that several side effects impacted their social life, with some participants socializing less frequently due to a "couldn't be bothered" attitude. "Shakes" limited participation in activities including eating out with friends for fear of spilling food. Tiredness, being on a set routine with the need for a 12-hour gap between medicines inhibited socialization and made patients inflexible, with one using the scheduling as an excuse for not socializing. Many participants reported that the quality of their relationships suffered with less socializing. Fear of infections, particularly right after transplant, prevented participants from going out to public places like the cinema or visiting friends with sick children. The public showed lack of empathy toward participants as they were ignorant of the side effects associated with treatment:

“[...] would never order that if someone else was around. Because, I would just throw it all over the table or throw it all over myself. Chopsticks are a real challenge" (Female, age 36)

"[...] you go back to living a virtually normal life [...] it also impacts on your nearest and dearest." (Female, age 60)

\section{Psychological impact of IT}

The psychological impact of side effects was multifaceted. At the more severe end, participants reported depression or easily getting "snappy". Side effects like unwanted facial hair, weight gain, and sweating were embarrassing. At the other end, participants were anxious about the impact of secondary effects like arthritis on their ability to ride a bike, skin cancer on swimming or their ability to read with poor concentration. The burden of medication, length of illness, and the impact of side effects were reported as the cause of some participants' change of personality. However, coping with side effects was considered a price worth paying for the improvement in health:

"I find myself snapping [...] I never used to before."

(Female, age 57)

"I've always been so active and quite bubbly and cheer-

ful, and slim. I'm not slim anymore." (Female, age 60)

"It's a small price to pay for what you get in return."

(Male, age 52)

"I'm just thankful to take any immunosuppressants

because it's keeping me alive." (Female, age 60)

\section{Conceptual framework}

The themes regarding the impact of IT on HRQoL summarized from the focus groups and supported by the literature review were depicted in a conceptual map. The conceptual framework of IT-specific HRQoL included two domains and three subdomains. The two domains are the side-effects associated with IT and the general impact of being on IT, while the three subdomains are the psychological impact of IT, the impact of IT on work life, and also on social life, which altogether contribute to the QoL of RT patients under immunosuppressants. The conceptual model is shown in Figure 1.

\section{Discussion}

The majority of participants in this study were well informed about their medication, understood the importance of being adherent to IT toward their well-being and were positive about treatment. They accepted the necessity of IT with the understanding that the medication conferred side effects.

Nurses and patients in the focus groups identified a variety of factors influencing adherence to medications and contributing to non-adherence. Nurses reported that conflicts with the patient's lifestyle were a prime source of non-adherence, while the reasons patients gave for their non-adherence can be categorized mainly under: forgetfulness, the result of disruption to routine, and being away from home. These behavioral factors add to the documented leading reasons for adult non-adherence to IT, which include forgetfulness, cost, unpleasant side-effects, and the regimen complexity. ${ }^{20-23}$ Other authors reported reasons for non-adherence due to social factors, psychological impact of the medication ${ }^{24}$ and poor patient cognition. ${ }^{25}$ In addition, more frequent dosing was associated with decreased adherence, Weng et al. ${ }^{26}$ Our results are consistent with the barriers to adherence identified in the Gordon et $\mathrm{al}^{18}$ study that included being busy, 


\section{Immunosuppressant therapy*}

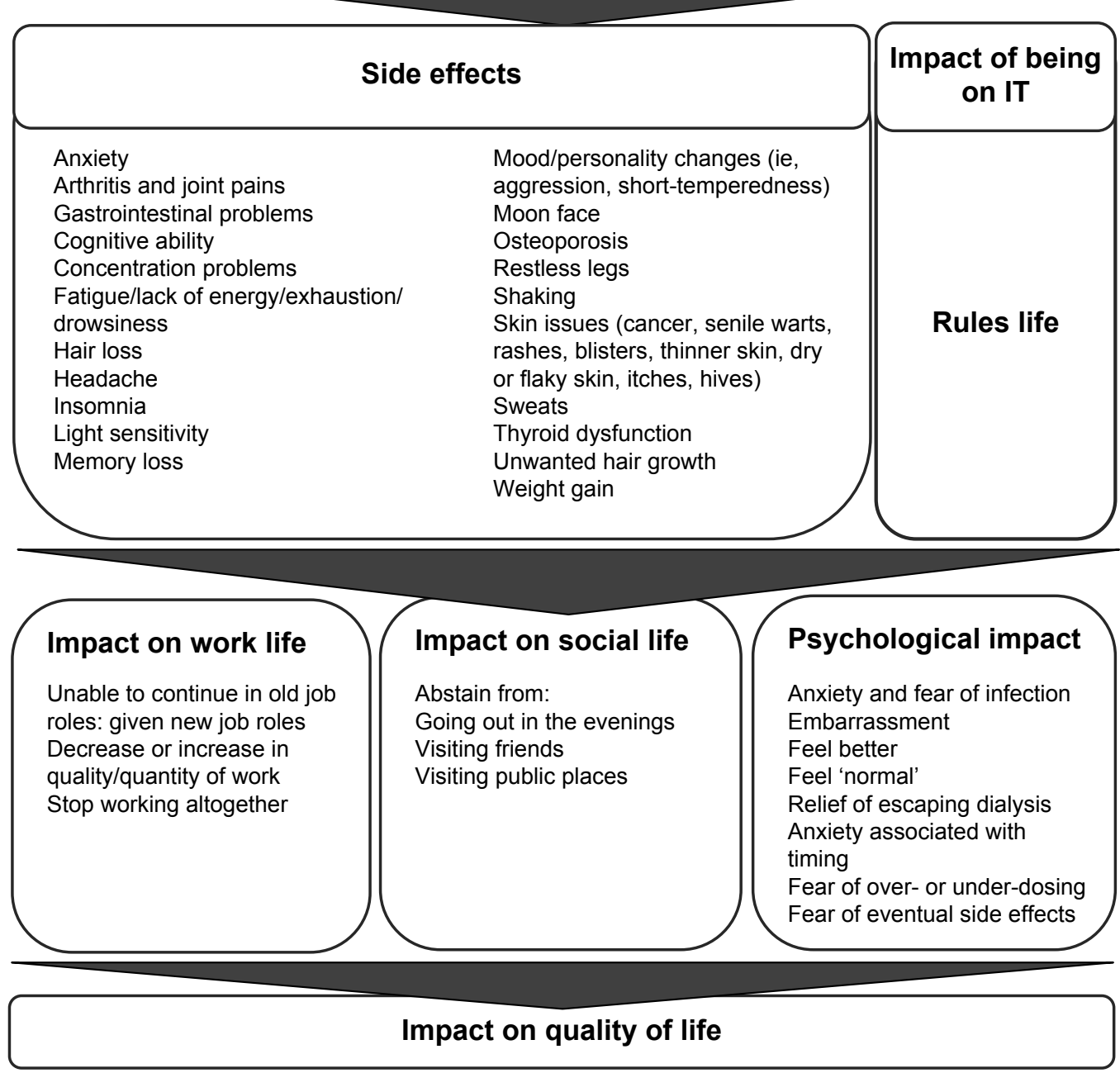

Figure I Conceptual framework of the impact of IT on quality of life.

Notes: Factors influencing quality of life were included in the model based on the themes that emerged during the focus groups. *Elderly $(>68$ years), children $(<18$ years), and young adult ( $18-25$ years) patients are not included in this analysis.

Abbreviation: IT, immunosuppressant therapy.

forgetting to bring medicines with them, being sick, and being away from home.

The strategies patients used to adhere to their regimen included the use of pill counts, alarms, and recruiting reminders. These strategies were also reported by De Bleser et al. ${ }^{27}$ In a similar study by Russell et al, ${ }^{28}$ the authors reported that patients also made use of visual cues and external aids such as clocks to remain adherent.

The recommended 12-hour gap for twice-daily regimen was difficult to adhere to and impacted on patients' activities. Indeed some got distracted - did not adhere to the 12-hour gap or failed to take either of their doses. The timing was limiting to patients' activities, compelling them to stop their activity and return home in time for their medication. Some participants adopted a "convenient timing", taking their medication first thing in the morning and last thing before going to bed. Our findings showed that participants in Nottingham were more adherent than their counterparts in London. The larger number of subjects on the once-daily dosing could be one explanation of the greater adherence shown in the Nottingham participants. The once-daily dosing is the treatment of choice at the Nottingham kidney transplant unit and was explained by the nurses as a way to improve adherence, especially in the problematic groups. The evening dose for subjects on the twice-daily dosing seemed to conflict more with their lifestyles, particularly when socializing opportunities presented 
themselves. Non-adherent participants either failed to take the treatment or did not adhere to the timing. As much as patients valued the "second chance" provided by the transplant, their graft remained at risk of loss as long as they were not fully adherent. Although participants reported taking other co medications (eg, medication for hypertension) with their IT, the reduced burden associated with taking the once-daily dosing accounts for a large majority of subjects on the twice-daily dosing preferring the alternative regimen. This is consistent with the Guirado et $\mathrm{al}^{29}$ study in which $99.4 \%$ of the patients converted from twice-daily immediate release tacrolimus to a once daily prolonged release tacrolimus, preferred the once-daily dosing.

In a Spanish survey of lung and RT patients, ${ }^{30}$ the most common barrier to adherence reported was daily medication intake, also considered as a lifestyle restriction in $25 \%$ of participants. In addition, most patients preferred to suppress the evening dose if given the choice. A survey by Ichimaru et $\mathrm{al}^{31}$ on Japanese RT patients supported the findings that the evening dose may be problematic to IT adherence. These authors also demonstrated differential adherence among patients on different dosing regimens, reporting $87.5 \%$ and $76.7 \%$ adherence for the morning and the evening dose, respectively. This is in line with a recent randomized controlled study by Kuypers et $\mathrm{al}^{7}$ that reported significantly higher adherence rates on the once-daily prolonged release tacrolimus in comparison with the twice-daily alternative. Even with similar evidence, recent study on the subject like Sabbatini et $\mathrm{al}^{32}$ conclude that major efforts in preventing non-adherence in RT are needed beyond reducing the pill burden to calcineurin inhibitors.

Interestingly, patients do make the distinction between deliberate non-adherences vs accidental lapses. This distinction between intentional and unintentional adherence has been explored with transplant patients and it was shown that it can have important implications for clinical practice and intervention strategies to improve medication adherence. ${ }^{17}$ Non-adherence is "unintentional" when it is not deliberate, with the most frequently cited reason being a failure to remember. In a cross-sectional study including 218 RT patients, $62.4 \%$ of patients admitted unintentional non-adherence mainly due to forgetfulness. ${ }^{17}$ Lapses were shown to be closely related to treatment factors (eg, dose, complexity). ${ }^{33}$ Authors concluded that efforts to increase adherence should be implemented by promoting strategies to decrease forgetfulness. ${ }^{34}$ Our study supports the evidence that reducing the chance that patients omit one of several doses by decreasing the number of daily doses is likely to be efficient on the unintentional aspect of non-adherence and would be less complex to implement than trying to change the patient's behavior.

Although participants were often unable to disentangle the side effects due to other medications from those associated with IT, this study provides insight into the specific components of HRQoL impacted on by IT in RT patients. To our knowledge, this is the first study to conceptually map the range and nature of the impact of IT on HRQoL and investigate patterns of association unique to specific patient factors. For RT transplants, the main impacts of IT on HRQoL are in terms of psychological well-being, social activity, and work; these were directly correlated to the severity of side-effects experienced and the complex medical regimen to which patients should comply. The embarrassment of having facial hair, sensitivity to body size/shape, and anxiety associated with dose omission or exposure to the sun had a negative impact on the patients' social activity and their psychological well-being. The patients' physical QoL was affected by fatigue, gastrointestinal problems, shaking, and skin problems. Side effects like sweating, shaking, loss of ability to concentrate, and fatigue impacted on their capacity to perform certain roles at work. Consequently, it was unsurprising that some participants had been given changed roles or indeed had moved jobs as a direct result of adverse events. Nonetheless, participants saw adherence to IT as a price worth paying to lead a "more normal" life and avoid dialysis.

Participants on the twice-daily regimen reported a similar side effect profile to those reported by others on the once-daily regimen. This is consistent with the findings of Alloway et $\mathrm{al}^{135}$ where the authors reported on conversion from twice-daily standard-release tacrolimus to once-daily prolonged-release tacrolimus in maintenance RT recipients. After follow-up, patients who switched to the once-daily formulation reported the same adverse event profile as those on the twice-daily. The switch from twice-daily to once-daily regimens may not improve the impact of the side effects of immunosuppressive medication on the patients' QoL. However, the burden of medication and the constant anxiety associated with trying to adhere to the timing and the dosage of IT medication were contributing to a lower psychological QoL among patients. From the discussions with both patients and nurses, it emerged that switching to a once-daily regimen would be more convenient, as it would reduce the burden of medication and provide better opportunities for patients to combine their medication with their lifestyles. Furthermore, IT will be less of a hindrance to their 
social activities, thus improving adherence to IT and bringing about better HRQoL outcomes among patients as supported by evidence in Sabbatini et al. ${ }^{32}$ Also, it could be expected that this improvement of HRQoL would be even more valued by young adults for whom the impact of immunosuppressants on their social life, compounded by challenges associated with the transfer and transition from child to adult care, ${ }^{36-38}$ is a major reason for non-adherence.

The limitations of this study are those attributable to qualitative research. First, the sample was small and purposively selected, which does not allow for statistical generalization. With the evidence of high prevalence of non-adherence among young adults $16-25$ years old, ${ }^{36}$ it is unfortunate that this group is not represented in the study, despite the huge recruitment effort. Furthermore, elderly patients $\geq 68$ years or patients with major physical dysfunction (eg, kidney failure) were not represented. Nevertheless, the sample was representative of the population of renal transplant patients in the middle ages (29-68 years old) and as such, the results can be generalized to this population. The focus groups provided a wealth of insights into the motivation, attitudes, perceptions, and behavior of patients that cannot easily be obtained by quantitative methods alone.

Second, the pressure arising from both the value placed on the transplanted kidney, the feeling of gratitude, and being beholden to the renal staff and donors may make it very difficult to admit to non-adherence, particularly in front of other transplant recipients. As with all focus groups, social pressures to conform to an ideal image are a potential source of distortion as reported by Orr et al. ${ }^{16}$ It may be thus more likely for patients to admit to forgetfulness rather than accept deliberate non-adherence, leading to its being overemphasized in this context.

\section{Conclusion}

This study provides qualitative evidence about the barriers to IT adherence and the components of HRQoL that are important from the perspective of RT patients. We developed a conceptual framework of IT-HRQoL in RT transplants, including social, psychological, and work-life domains, which can be used to inform the development of a new ITspecific measure of HRQoL in RT patient for use in headto-head clinical trials or observational studies.

Patients' reasons for not adhering to treatment recommendations can provide insight for tailoring a treatment to patients' values and needs. Specifically, this study suggests that patients strongly value adherence to IT medication and see a change in the regimen from twice-daily to once daily as one possible way to improve their adherence to IT and their QoL.

\section{Acknowledgments}

This study was funded by Astellas Pharmaceuticals Europe Ltd. We thank Dr Emna El Hammi who provided medical writing assistance on behalf of Evidenz.

\section{Author contributions}

NAH designed the study. NAH and FCS conducted the interviews and managed the literature searches and analyses, and FCS wrote the manuscript. All authors contributed toward data analysis, drafting and revising the paper and agree to be accountable for all aspects of the work.

\section{Disclosure}

This study was funded by Astellas Pharmaceuticals Europe Ltd. The sponsor had no role in the study design; the collection, analysis and interpretation of data. Gorden Muduma and Isaac Odeyemi are full-time employees of Astellas Pharmaceuticals Europe Ltd. Both Gorden Muduma and Isaac Odeyemi declare that they have no conflicts of interest in this work. Francis C Shupo, Sophie Dam, Natalia A Hawken, Samuel Aballéa, and Mondher Toumi are fulltime employees of Creativ-Ceutical Ltd, which received consultancy fees from Astellas Pharmaceuticals Europe Ltd for services in conducting the research and preparing the manuscript. All authors employed with Creativ-Ceutical Ltd declare that they have no conflict of interest in this work.

\section{References}

1. Port FK, Wolfe RA, Mauger EA, Berling DP, Jiang K. Comparison of survival probabilities for dialysis patients vs cadaveric renal transplant recipients. JAMA. 1993;270:1339-1343.

2. Tanriover B, Stone PW, Mohan S, Cohen DJ, Gaston RS. Future of medicare immunosuppressive drug coverage for kidney transplant recipients in the United States. Clin J Am Soc Nephrol. 2013;8:1258-1266.

3. Maclean JR, Pfister M, Zhou Z, Roy A, Tuomari VA, Heifets M. Quantifying the impact of nonadherence patterns on exposure to oral immunosuppressants. Ther Clin Risk Manag. 2011;7:149-156.

4. Constantiner M, Cukor D. Barriers to immunosuppressive medication adherence in high-risk adult renal transplant recipients. Dial Transpl. 2011;40:60-66.

5. Denhaerynck K, Dobbels F, Cleemput I, et al. Prevalence, consequences, and determinants of nonadherence in adult renal transplant patients: a literature review. Transpl Int. 2005;18:1121-1133.

6. Nevin TE, Thomas W. Quantitative patterns of Azathioprine adherence after renal transplantation. Transplantation. 2009;711-718.

7. Kuypers DR, Peeters PC, Sennesael JJ, et al. Improved adherence to tacrolimus once-daily formulation in renal recipients: a randomized controlled trial using electronic monitoring. Transplantation. 2013;95: $333-340$

8. Butler JA, Roderick P, Mullee M, Mason JC, Peveler RC. Frequency and impact of nonadherence to immunosuppressants after renal transplantation: a systematic review. Transplantation. 2004;77: 769-776. 
9. Sellares J, de Freitas DG, Mengel M, et al. Understanding the causes of kidney transplant failure: the dominant role of antibody-mediated rejection and nonadherence. Am J Transplant. 2012;12:388-399.

10. Vlaminck H, Maes B, Evers G, et al. Prospective study on late consequences of subclinical non-compliance with immunosuppressive therapy in renal transplant patients. Am J Transplant. 2004;4:1509-1513.

11. Germin-Petrovic D, Mesaros-Devcic I, Lesac A, et al. Health-related quality of life in the patients on maintenance hemodialysis: the analysis of demographic and clinical factors. Coll Antropol. 2011;35:687-693.

12. Franke GH, Trampenau C, Reimer J. Switching from cyclosporine to tacrolimus leads to improved disease-specific quality of life in patients after kidney transplantation. Transplant Proc. 2006;38:1293-1294.

13. Prasad GV, Nash MM, Keough-Ryan T, Shapiro RJ. A quality of life comparison in cyclosporine- and tacrolimus-treated renal transplant recipients across Canada. J Nephrol. 2010;23:274-281.

14. Calia R, Lai C, Aceto P, et al. Effects of switching from twice-daily to once-daily tacrolimus formulation on quality of life, anxiety, and transplant benefit perception after kidney transplantation. Transplant Proc. 2011;43:1020-1023.

15. Gorevski E, Succop P, Sachdeva J, et al. Is there an association between immunosuppressant therapy medication adherence and depression, quality of life, and personality traits in the kidney and liver transplant population? Patient Prefer Adherence. 2013;7:301-307.

16. Orr A, Orr D, Willis S, Holmes M, Britton P. Patient perceptions of factors influencing adherence to medication following kidney transplant. Psychol Health Med. 2007;12:509-517.

17. Griva K, Davenport A, Harrison M, Newman SP. Non-adherence to immunosuppressive medications in kidney transplantation: intent vs. forgetfulness and clinical markers of medication intake. Ann Behav Med. 2012;44:85-93.

18. Gordon EJ, Gallant M, Sehgal AR, Conti D, Siminoff LA. Medicationtaking among adult renal transplant recipients: barriers and strategies. Transpl Int. 2009;22:534-545.

19. Kitzinger J. Qualitative research. Introducing focus groups. BMJ. 1995;311:299-302.

20. Moore M, Zelikovsky N, Mindell JA. A pilot study of sleep and medication adherence in adolescent kidney transplant recipients. Poster presented at: Sleep Conference: 24th Annual Meeting of the Associated Professional Sleep Societies, LLC, SLEEP 2010; June 5-9, 2010; San Antonio, TX, USA.

21. Normen M, Surendran V, Ganesan P, Rajendranath R, Sagar TG. Patients' perspectives on adherence to treatment in chronic myeloid leukemia. In: Psycho-Oncology Conference: 15th World Congress of Psycho-Oncology of the International Psycho-Oncology Society, IPOS; November 4-8, 2013, Rotterdam, the Netherlands.

22. Kugler C, Gottlieb J, Dierich M, et al. Significance of patient selfmonitoring for long-term outcomes after lung transplantation. Clin Transplant. 2010;24:709-716.

23. Evans RW, Applegate WH, Briscoe DM, et al. Cost-related immunosuppressive medication nonadherence among kidney transplant recipients. Clin J Am Soc Nephrol. 2010;5:2323-2328.

24. Ruth ND, Legarda M, Smith M, et al. Long term outcome after liver transplant - a 15 year retrospective review. In: Hepatology Conference: 64th Annual Meeting of the American Association for the Study of Liver Diseases: The Liver Meeting 2013; November 1-5, 2013; Washington, DC, USA

Patient Preference and Adherence

\section{Publish your work in this journal}

Patient Preference and Adherence is an international, peer-reviewed, open access journal that focuses on the growing importance of patient preference and adherence throughout the therapeutic continuum. Patient satisfaction, acceptability, quality of life, compliance, persistence and their role in developing new therapeutic modalities and compounds to optimize
25. Guimaraes Marcelino CA, da Cruz DM. The effectiveness of interventions to manage treatment adherence in adult heart transplant patients: a systematic review protocol. JBI Database of System Rev Implement Rep. 2013;11:2013.

26. Weng FL, Israni AK, Joffe MM, et al. Race and electronically measured adherence to immunosuppressive medications after deceased donor renal transplantation. J Am Soc Nephrol. 2005;16:1839-1848.

27. De Bleser L, Matteson M, Dobbels F, Russell C, De Geest S. Interventions to improve medication-adherence after transplantation: a systematic review. Transpl Int. 2009;22:780-797.

28. Russell CL, Kilburn E, Conn VS, Libbus MK, Ashbaugh C. Medicationtaking beliefs of adult renal transplant recipients. Clin Nurse Spec. 2003;17:200-208

29. Guirado L, Cantarell C, Franco A, et al. Efficacy and safety of conversion from twice-daily to once-daily tacrolimus in a large cohort of stable kidney transplant recipients. Am J Transplant. 2011;11:1965-1971.

30. Morales JM, Varo E, Lazaro P. Immunosuppressant treatment adherence, barriers to adherence and quality of life in renal and liver transplant recipients in Spain. Clin Transplant. 2012;26:369-376.

31. Ichimaru N, Kakuta Y, Abe T, et al. Treatment adherence in renal transplant recipients: a questionnaire survey on immunosuppressants. Transplant Proc. 2008;40:1362-1365.

32. Sabbatini M, Garofalo G, Borrelli S, et al. Efficacy of a reduced pill burden on therapeutic adherence to calcineurin inhibitors in renal transplant recipients: an observational study. Patient Prefer Adherence. 2014;8:73-81.

33. Lehane E, McCarthy G. Intentional and unintentional medication non-adherence: a comprehensive framework for clinical research and practice? A discussion paper. Int J Nurs Stud. 2007;44:1468-1477.

34. Franke GH, Reimer J, Philipp T, Heemann U. Aspects of quality of life through end-stage renal disease. Qual Life Res. 2003;12:103-115.

35. Alloway R, Steinberg S, Khalil K, et al. Conversion of stable kidney transplant recipients from a twice daily Prograf-based regimen to a once daily modified release tacrolimus-based regimen. Transplant Proc. 2005;37:867-870.

36. Gajree S, Clancy M. The transition of young adult renal transplant recipients into adult care: a west of Scotland perspective. In: Transplant International Conference: 16th Congress of the European Society for Organ Transplantation, ESOT; September 8-11, 2013; Vienna, Austria.

37. Lim KB, Hartono JL, Dan YY, et al. Adherence to immunosuppressive therapy in adult and adolescent liver transplant recipients in a multiethnic Asian Centre: a questionnaire survey. In: Hepatology Conference: 65th Annual Meeting of the American Association for the Study of Liver Diseases: The Liver Meeting 2014; November 8-10, 2014; Boston, MA, USA.

38. Annunziato RA, Arrato N, Rubes M, Arnon R. The importance of mental health monitoring during transfer to adult care settings as examined among paediatric transplant recipients. J Paediatr Child Health. $2015 ; 51: 220-222$ clinical outcomes for existing disease states are major areas of interest for the journal. This journal has been accepted for indexing on PubMed Central. The manuscript management system is completely online and includes a very quick and fair peer-review system, which is all easy to use. Visit http://www. ovepress.com/testimonials.php to read real quotes from published authors. 